\section{BIOLOGY OF MAMMALS}

Life of Mammals

By Prof. J. Z. Young. Pp. $x v+820$ (338 figures). (Oxford: Clarendon Press ; London : Oxford University Press, 1957.) 84s. net.

"THE Life of Mammals" is in a sense a sequel to Prof. Young's "The Life of Vertebrates" published seven years ago, and is an equally massive work. In conception it is entirely original, drawing its subject-matter both from medical anatomy and physiology and from vertebrate and experimental zoology. It is a systematic text-book full of factual information, and will be extremely useful as a work of reference ; but it also characteristically presents an important central theme running through the whole book, which is to reveal the fundamentally mechanical nature of living systems, and of their remarkable powers of self-regulation or homeostasis. Prof. Young outlines this theme in Chapter 1 with admirable and stimulating clarity, using the analogies of man-made machines and communication devices with their servo-mechanisms and attainment of regulation by the use of feed-back. He returns to it time and sgain in the subsequent pages.

In all there are forty-seven chapters arranged in a morphological sequence, starting with the integument and the mechanical systems of the body, and proceeding next in turn to the digestive, circulatory, respiratory and excretory systems. These carry the reader to Chapter 16. Seven chapters follow on the nervous system and five on the various types of receptors; five more deal with endocrinology, and the remaining fourteen chapters are taken up with reproduction and embryology. A bibliography gives a small number of selected references for each chapter, and finally there is an index of 15 pages (30 columns), which incidentally seems barely generous enough for so large a book. For the convenience of those to whom it will be a standard work of reference an index double the size would not have been excessive.

The one obvious criticism to be made stems from the title, which may very well lead the reader to expect an entirely different sort of book. The emphasis here is on life-processes, illustrated for the most part by one or both of two selected types, the primate (especially man) and the rabbit; and it must be admitted that occasionally an impression is given by the author that what applies to this selected material applies to the mammals as a whole, when this is by no means the case. There is actually very little on either the natural history of mammals or on their comparative anatomy and physiology, though these are the particular subjects which one might expect to form the main substance of such a book, judging from the title alone. Students who specialize in the study of mammals may be excused if they feel a momentary disappointment in discovering that, after all, they have still to wait for the particular kind of text-book on mammalian zoology in English that they so badly need; but they may remember that Prof. Young has previously devoted more than two hundred pages to a comparative review of the marmmals in "The Life of Vertebrates".

"The Life of Mammals" will commend itself to anatomists and physiologists, partly for the great amount of information it contains which is either new or has never before appeared in a text-book. This applies with perticular force to the second half of the book, dealing with the nervous and endocrine systems and with development. But over and above the value of having so much recent material from very diverse sources collected together, they will benefit from the recurring sections in which the author pauses to interpret the facts and explore the general principles or ideas which emerge from them; these are frequently highly original and stimulating, and succeed to an important degree in extending the boundaries of the reader's insight and understanding. As might be expected, the text is very readable. The book can be commended equally well to students of zoology, some of whom may discover in it with advantage many of the classical facts of medical anatomy and physiology for the first time.

Great care has been taken with the illustrations, a large number of which are new and have been specially drawn with considerable skill; they include a very useful series on the anatomy of the rabbit (for which a finding index would be a welcome addition). The general standard of production is excellent, and in relation to the enormous labour of producing such a book the number of minor errors is small. It may be hoped that the complicated task of revising it at intervals to keep pace with advancing knowledge will prove to be possible for many years to come.

V. C. WYNNE-EDWARdS

\section{LANDMARK IN COAL SCIENCE}

\section{Coal Science}

Aspects of Coal Constitution. By Prof.' D. W. Van Krevelen and J. Schuyer. Pp. xii +352. (Amsterdam: Elsevier Publishing Company; London : Cleaver-Hume Press, Ltd. ; Princeton, N.J.: D. Van Nostrand Company, Inc., 1957.) 55s.

A STUDY of coal in all its varieties involves most of the pure sciences. The basic economic importance of coals, and especially the baffling complexity of some of their properties, justify the treatment of coal science as a separate branch. Coals are porous and amorphous, and appear to consist of aperiodic macromolecules; few standard techniques can be applied to their study without modification, and the results are frequently ambiguous or less informative than those obtained with simpler organic compounds. Special methods have been developed, many unorthodox and most containing an element of empiricism.

It is not easy to assess the significance of the reported results, which vary widely in quality. Owing to the rapid current advance in the subject and the increase in team effort throughout the world, a simple exposition of coal science as a whole is a compelling need, but its satisfaction is correspondingly difficult. The text-book under review, in spite of shorteomings to be expected in a pioneer venture, must be acclaimed as a considerable achievement in this direction.

Coal petrology and systematies together with related physical and colloidal studies-primarily observational approaches-are concisely and authoritatively treated in Part 1 ("Coal in its Various Aspects"); and chemical studies of coal constitution -primarily experimental-are fully described in Part 2 ("Constitution of the Coal Matrix"). It is an especial merit of this book that a powerful attempt is made to integrate these two major branches of coal science, hitherto independent developments.

In Part 2 there is a full description of the novel methods of statistical structural analysis-based on 